\title{
Article \\ High Reoperation Rate in Mobile-Bearing Total Ankle Arthroplasty in Young Patients
}

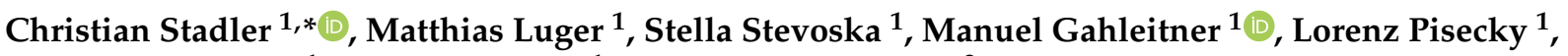 \\ Tobias Gotterbarm ${ }^{1}$, Antonio Klasan ${ }^{1}$ and Matthias C. Klotz ${ }^{2}$
}

1 Department for Orthopaedics and Traumatology, Med Campus III, Kepler University Hospital GmbH, Johannes Kepler University Linz, Krankenhausstr. 9, 4020 Linz, Austria; matthias.luger@kepleruniklinikum.at (M.L.); stella.stevoska@kepleruniklinikum.at (S.S.); manuel.gahleitner@kepleruniklinikum.at (M.G.); lorenz.pisecky@kepleruniklinikum.at (L.P.); tobias.gotterbarm@kepleruniklinikum.at (T.G.); antonio.klasan@kepleruniklinikum.at (A.K.)

2 Marienkrankenhaus Soest, Orthopaedics and Trauma Surgery, Widumgasse 5, 59494 Soest, Germany; m.klotz@hospitalverbund.de

* Correspondence: christian.stadler@kepleruniklinikum.at

check for updates

Citation: Stadler, C.; Luger, M.; Stevoska, S.; Gahleitner, M.; Pisecky, L.; Gotterbarm, T.; Klasan, A.; Klotz, M.C. High Reoperation Rate in Mobile-Bearing Total Ankle Arthroplasty in Young Patients. Medicina 2022, 58, 288. https:// doi.org/10.3390/medicina58020288

Academic Editor: Vassilios S. Nikolaou

Received: 29 December 2021 Accepted: 11 February 2022 Published: 14 February 2022

Publisher's Note: MDPI stays neutral with regard to jurisdictional claims in published maps and institutional affiliations.

Copyright: (C) 2022 by the authors. Licensee MDPI, Basel, Switzerland. This article is an open access article distributed under the terms and conditions of the Creative Commons Attribution (CC BY) license (https:// creativecommons.org/licenses/by/ $4.0 /)$.

\begin{abstract}
Background and Objectives: Due to inferior survival rates compared to hip and knee arthroplasty, total ankle arthroplasty (TAA) was previously mainly recommended for older and less active patients. However, given the encouraging survival rates and clinical outcomes of modern generations of TAA, some authors have also advocated TAA in young patients. Thus, the aim of this study was to evaluate age related reoperation, revision and survival rates of third-generation mobile-bearing TAAs. Materials and Methods: In this retrospective study, 224 consecutive TAA patients with a minimum follow up (FU) of 2 years were analyzed. Patients were retrospectively assigned to two study groups (Group A: age < 50 years; Group B: age $\geq 50$ years). Revision was defined as secondary surgery with prothesis component removal, while reoperation was defined as a non-revisional secondary surgery involving the ankle. Results: After a mean FU of $7.1 \pm 3.2$ years, the reoperation rate (Group A: $22.2 \%$; Group B: $5.3 \% ; p=0.003$ ) and revision rate (Group A: 36.1\%; Group B: $13.8 \% ; p=0.003$ ) were higher within Group A. An age of under 50 years at time of surgery was associated with higher reoperation (odds ratio (OR): 6.54 (95\% CI: 1.96-21.8); $p=0.002$ ) and revision rates (OR: 3.13 (95\% CI: 1.22-8.04); $p=0.018)$. Overall, lower patient age was associated with higher reoperation $(p=0.009)$ and revision rates $(p=0.001)$. Conclusions: The ideal indication for TAA remains controversial, especially regarding patient age. The findings of this study show high reoperation and revision rates in patients aged under 50 years at time of surgery. Therefore, the outcomes of this study suggest that the indication for TAA in young patients should be considered very carefully and that the association between low patient age and high reoperation rate should be disclosed to all eligible patients.
\end{abstract}

Keywords: total ankle arthroplasty; ankle replacement; ankle arthritis; endoprosthetics; arthrodesis; salto mobile-bearing

\section{Introduction}

While arthroplasty is the gold standard for the treatment of end-stage osteoarthritis (OA) in the hip and knee, arthrodesis has been the treatment of choice for the ankle in the past [1,2]. In recent years, previous studies have reported encouraging survival rates for newer generations of total ankle arthroplasties (TAAs), so the arthroplasty of the ankle is gaining in popularity [3-9]. Nevertheless, the decision between TAA and ankle arthrodesis has to be carefully considered for each patient individually-especially in case of severe instability or deformity [10]. The intended advantages of TAA are good residual mobility and thus improved function compared to arthrodesis [11,12]. In addition, an improved mobility of the ankle joint is intended to reduce the risk of subsequent OA in adjacent joints [11-16]. Due to its inferior survival rates compared to hip and knee replacement, 
TAA was mainly recommended for older and less active patients in the past [17-19]. However, some recent publications have advocated for various TAA implants in young patients [17-23]. Gaugler et al. and Lee et al. reported no significant impact of age at time of surgery on the prothesis survival or reoperation rates for Hintegra TAA (Allegra Orthopaedics, Sydney, NSW, Australia) $[17,20]$. Rodrigues-Pinto et al. analyzed the agerelated outcomes of the Salto mobile-bearing TAA (Tornier SA, Saint Ismier, France) within a mean follow up (FU) of 3.4 years and found no significant age-related differences in complication and prothesis survival rates [18]. Currently, there are no reports available regarding age-related reoperation rates and survival for the Salto mobile-bearing TAA with a mean FU of more than 5 years and a large study population.

Thus, the aim of this study was to evaluate the age-related revision, reoperation, implant survival rates of the Salto mobile-bearing TAA with a long-term FU in a large cohort.

\section{Materials and Methods}

\subsection{Study Type and Population}

This was a retrospective cohort study. Inclusion criteria for this study were the implantation of a third-generation Salto mobile-bearing TAA (Tornier SA, Saint Ismier, France) between March 2002 and November 2015 with a minimum follow up (FU) of 2 years. A total of 275 TAAs were consecutively implanted within the time period mentioned above by two senior orthopedic surgeons, each with more than 10 years of experience in foot and ankle surgery. Within the FU period, a total of 11 patients died and 40 protheses did not meet the inclusion criteria mentioned above, resulting in an overall study population of 224 TAAs. The study population was divided into two subgroups retrospectively according to the patient's age at time of surgery. Patients aged under 50 years were assigned to Group A, and patients aged 50 years or above were assigned to Group B (Figure 1) [18]. Contraindications for TAA were physically demanding professions, excessive sports on a regular basis, severe neurological disorders, uncontrolled diabetes mellitus, poor peripheral blood circulation, inadequate bone stock, severe instability, and history of recent ankle infection $[24,25]$. The study center was a university hospital in Austria.

Total Ankle Arthroplasties performed $(n=275)$

Figure 1. Flowchart regarding formation of the study population and its allocation in the two study subgroups dependent on the patient's age at time of surgery (Group $\mathrm{A}=$ age under 50 years; Group $B=$ age above 50 years).

\subsection{Preoperative Preparation, Surgical Technique, Postoperative Care and Follow up}

Preoperatively, a thorough clinical examination of the patient and the ankle was performed by the surgeon. Prior to skin incision, antibiotic prophylaxis was administered as an intravenous single shot ( $1.5 \mathrm{~g}$ of cefuroxime followed by $600 \mathrm{mg}$ of clindamycin for 
patients with a penicillin allergy). The Salto mobile-bearing TAA was implanted using an anterior approach to the ankle's articular capsule between the M. tibialis anterior's and the M. extensor hallucis longus' tendon. After chiseling surrounding osteophytes (if present), the components of the prothesis were implanted according to the manufacturer's instructions $[25,26]$. After performing the TAA, an adequate range of motion (ROM) of the ankle joint was intraoperatively checked prior to wound closure. A short leg cast was applied to every patient for a total of six weeks after finishing surgery in the operation room immediately after wound closure and sterile wound dressing. No weightbearing was recommended to every patient for two weeks, followed by partial weightbearing for another two weeks and full weightbearing for the last two weeks prior to the removal of the short leg cast. Venous thrombosis prophylaxis was postoperatively ensured throughout the entire first six weeks.

Physiotherapy was provided to every patient from day one after surgery to instruct the correct usage of crutches and to mobilize patients, train coordinative skills, and prevent excessive muscular atrophy of the not immobilized lower extremities. Patients stayed an average of $9.4 \pm 3.2$ days at the hospital and were discharged once adequate local conditions at the operated ankle including swelling and wound status were achieved. Patients were checked up at the outpatient clinic two weeks after surgery for suture removal and the application of a circulated short leg cast. Further check-ups at the outpatient clinic were recommended to every patient four weeks, six weeks, three months, and one year after surgery. After the first postoperative year, additional check-ups were recommended after every two years.

Following the removal of the short leg cast, physiotherapy was suggested to every patient in order to improve the ankle's ROM as effectively as possible and to counteract muscular atrophy caused by the postoperative immobilization of the operated leg. Full weight bearing was permitted after the removal of the short leg cast, but the avoidance of physical activities with high impact on the ankle was recommended to every patient.

Patient records were retrospectively screened for complications that led to secondary surgery. As for the secondary surgeries following the primary TAA, the definitions introduced by Henricson et al. were applied [27]. Therefore, revision was defined as secondary surgery with the removal of at least one of the prothesis' components and reoperation was defined as secondary surgery of the ankle without the removal of one of the prothesis' components except for an incidental exchange of the polyethylene inlay. Secondary surgeries related to the TAA but not involving the actual joint were defined as additional procedures.

End of follow up was defined as the date of secondary surgery or as the date of the last check-up at the outpatient clinic if no adverse event with subsequent reoperation occurred.

\subsection{Statistical Analysis}

SPSS (version 27.0, IBM, Armonk, NY, USA) was used for the statistical analysis. The Kolmogorov-Smirnov test was performed to test for normality distribution. For metric-scaled data, the arithmetic mean and standard deviation were calculated, and these two parameters are reported as arithmetic mean value \pm standard deviation. KruskalWallis was used for the evaluation of differences between the study groups regarding nonnormally distributed parameters, and the $t$-test was used to analyze normally distributed parameters. The difference between nominally scaled parameters was analyzed using the chi square test. The survival analysis of the TAA was conducted via Kaplan-Meier analysis including the log rank test, with any reoperation and revision as the endpoint.

The analysis of associations between the patient characteristics and the rate of reoperations and revisions within the two study groups as dependent variables was performed with a binary logistic regression.

The level of significance was defined at $p \leq 0.05$. 


\section{Results}

\subsection{Demographic Characteristics}

The mean FU within the study population was $7.1 \pm 3.2$ years. The mean age within whole the study population was $61.4 \pm 11.8$ years, and it was $41.4 \pm 6.7$ years in Group A and $65.2 \pm 8.3$ years in Group B. The detailed characteristics of the study population and the indications for TAA are shown in Table 1.

Table 1. Baseline characteristics of the two study groups including the indications for TAA.

\begin{tabular}{|c|c|c|c|c|}
\hline $\begin{array}{l}\text { Baseline Characteristics of } \\
\text { the Study Population }\end{array}$ & $\begin{array}{c}\text { Overall } \\
(n=224)\end{array}$ & $\begin{array}{c}\text { Group A } \\
(n=36)\end{array}$ & $\begin{array}{l}\text { Group B } \\
(n=188)\end{array}$ & $p$-Value \\
\hline Mean follow up (years) & $7.1 \pm 3.2$ & $7.8 \pm 3.5$ & $7.0 \pm 3.1$ & 0.187 \\
\hline Mean age (years) & $61.4 \pm 11.8$ & $41.7 \pm 6.7$ & $65.2 \pm 8.3$ & $<0.001$ \\
\hline Female & 107 & 13 & 94 & 0.147 \\
\hline Male & 117 & 23 & 94 & 0.147 \\
\hline Right Ankle & 130 & 22 & 108 & 0.716 \\
\hline Left Ankle & 94 & 14 & 80 & 0.716 \\
\hline Mean body weight $(\mathrm{kg})$ & $80.9 \pm 17.0$ & $83.5 \pm 13.9$ & $80.4 \pm 17.5$ & 0.318 \\
\hline Mean body height $(\mathrm{cm})$ & $169.6 \pm 14.7$ & $174.4 \pm 8.1$ & $167.6 \pm 18.9$ & 0.002 \\
\hline Mean BMI & $28.0 \pm 4.3$ & $27.4 \pm 3.7$ & $28.2 \pm 4.4$ & 0.312 \\
\hline Mean ASA Score & $1.9 \pm 0.5$ & $1.5 \pm 0.6$ & $2.0 \pm 0.5$ & $<0.001$ \\
\hline Mean size tibial component & $1.9 \pm 0.8$ & $2.0 \pm 0.8$ & $1.9 \pm 0.8$ & 0.412 \\
\hline Mean size talar component & $1.6 \pm 0.6$ & $1.7 \pm 0.6$ & $1.5 \pm 0.6$ & 0.140 \\
\hline Mean size polyethylene inlay & $5.5 \pm 1.1$ & $5.3 \pm 1.2$ & $5.5 \pm 1.1$ & 0.237 \\
\hline $\begin{array}{c}\text { Indications for Total Ankle } \\
\text { Arthroplasty }\end{array}$ & $\begin{array}{l}\text { Overall } \\
(n=224)\end{array}$ & $\begin{array}{c}\text { Group A } \\
(n=36)\end{array}$ & $\begin{array}{l}\text { Group B } \\
(n=188)\end{array}$ & \\
\hline Posttraumatic osteoarthritis & 144 & 27 & 117 & 0.143 \\
\hline Primary osteoarthritis & 53 & 1 & 52 & 0.001 \\
\hline $\begin{array}{c}\text { Chronic inflammatory } \\
\text { diseases }\end{array}$ & 16 & 4 & 12 & 0.313 \\
\hline Prior infection & 5 & 2 & 3 & 0.016 \\
\hline Aseptic osteonecrosis & 3 & 2 & 1 & 0.141 \\
\hline Haemochromatosis & 3 & 0 & 3 & 0.445 \\
\hline
\end{tabular}

\subsection{Complications and Revisions}

Within the follow-up period, secondary surgery due to complications related to TAA including revisions, reoperations and additional procedures was performed in 60 patients $(26.7 \%)$. The detailed numbers regarding the complications that led to secondary surgery are shown in Table 2, and the types of the performed procedures are shown in Table 3. In 44 cases, more than one complication was addressed during the performed secondary surgery. In a total of six cases, the first revision surgery failed and was followed by the removal of the TAA. Following the removal of the TAA $(n=16)$, arthrodesis was performed in 14 cases ( 9 nail arthrodeses addressing the ankle joint and subtalar joint and 5 plate arthrodeses only addressing the ankle joint), and a revision TAA was performed in 2 cases.

In two cases, the indication for secondary surgery could not be determined because the procedure was performed in another hospital; in one case, no detailed information regarding the performed revisional surgery was available because it was performed in another hospital.

According to the definition of reoperation and revision mentioned above [27] the reoperation rate was $22.2 \%$ (8 reoperations within 36 ankles) within Group A and 5.3\% (10 reoperations within 188 ankles) within Group B $(p=0.003)$. The reoperation rate within the whole study population was 8.0\% (18 reoperations within 224 ankles). 
Table 2. Detailed numbers regarding the complications that led to secondary surgery. In a total of 35 cases, two or more of the complications listed below led to secondary surgery.

\begin{tabular}{cccc}
\hline Complication & $\begin{array}{c}\text { Group A } \\
(\boldsymbol{n}=\mathbf{2 1})\end{array}$ & $\begin{array}{c}\text { Group B } \\
(\boldsymbol{n}=\mathbf{3 9 )}\end{array}$ & $\begin{array}{c}\text { Overall } \\
(\boldsymbol{n}=\mathbf{6 0})\end{array}$ \\
\hline Osteolytic cysts & 10 & 10 & 20 \\
\hline Inlay fracture & 6 & 13 & 19 \\
\hline Ossifications & 10 & 7 & 11 \\
\hline Wear & 5 & 6 & 8 \\
\hline Soft tissue impingement & 3 & 2 & 5 \\
\hline Contracture/ROM-Limitation & 3 & 4 & 4 \\
\hline Acute infection & 0 & 2 & 2 \\
\hline Deep wound infection & 0 & 2 & 1 \\
\hline Inlay luxation & 0 & 1 & 1 \\
\hline Aseptic osteonecrosis & 0 & 1 & 1 \\
\hline Talonavicular OA & 0 & 1 & 1 \\
\hline Instability & 0 & 1 & 2 \\
\hline Achilles' tendon rupture & 0 & 1 & \\
\hline No information available & 1 & & 2 \\
\hline
\end{tabular}

Table 3. Detailed numbers regarding the types of procedures performed to address the complications related to TAA mentioned above. In a total of 44 cases, one or more procedures were performed within the secondary surgery.

\begin{tabular}{cccc}
\hline & $\begin{array}{c}\text { Group A } \\
(\boldsymbol{n}=\mathbf{2 1})\end{array}$ & $\begin{array}{c}\text { Group B } \\
(\boldsymbol{n}=\mathbf{3 9 )}\end{array}$ & $\begin{array}{c}\text { Overall } \\
(\boldsymbol{n}=\mathbf{6 0})\end{array}$ \\
\hline Inlay replacement & 18 & 27 & 45 \\
\hline Synovectomy & 10 & 14 & 24 \\
\hline Filling of osteolytic cysts & 9 & 8 & 17 \\
\hline Removal of ossifications & 10 & 7 & 16 \\
\hline Explantation & 6 & 10 & 14 \\
\hline Arthrodesis & 5 & 9 & 2 \\
\hline Revision prothesis & 1 & 1 & 3 \\
\hline Achilles' tendon lengthening & 2 & 3 & 2 \\
\hline Corrective osteotomy & 0 & 1 & 1 \\
\hline Ligamentous release & 1 & 1 & 1 \\
\hline Lateral ligament repair & 0 & 1 & 1 \\
\hline Achilles' tendon repair & 0 & 1 & 1 \\
\hline Talonavicular arthrodesis & 0 & 1 & 1 \\
\hline Flap Surgery & 0 & 1 & 1 \\
\hline Wound revision & 0 & 1 & 1 \\
\hline Subtalar arthrodesis & 0 & 0 & 2 \\
\hline No information available & & 1 & 3 \\
\hline
\end{tabular}

The revision rate was 36.1\% (13 revisions within 36 ankles) within Group A and 13.8\% (26 revisions within 188 ankles) within Group B $(p=0.003)$. The revision rate within the whole study population was 17.4\% (39 revisions within 224 ankles). 
Within Group A, the rate of all secondary procedures including revisions, reoperations and additional procedures related to TAA was 58.3\% (21 secondary procedures within 36 ankles), and it was $26.2 \%$ (39 secondary procedures within 149 ankles) within Group B $(p<0.001)$. The overall rate of secondary procedures within the whole study population was $26.8 \%$ (60 secondary procedures within 224 ankles).

\subsection{Survival Analysis and Regression Analysis}

The Kaplan-Meier survival analysis with reoperation as the endpoint showed that the 5-year survival rate was $90.9 \% \pm 5.0 \%$ for Group A and $96.5 \% \pm 1.4 \%$ for Group B. The 7-year survival rate was $90.9 \% \pm 5.0 \%$ for Group A and $94.2 \% \pm 1.9 \%$ for Group B; see Figure 2a. The difference between the prothesis survival of Groups A and B with reoperation as the endpoint was significant according to the performed log rank test $(p=0.007)$.

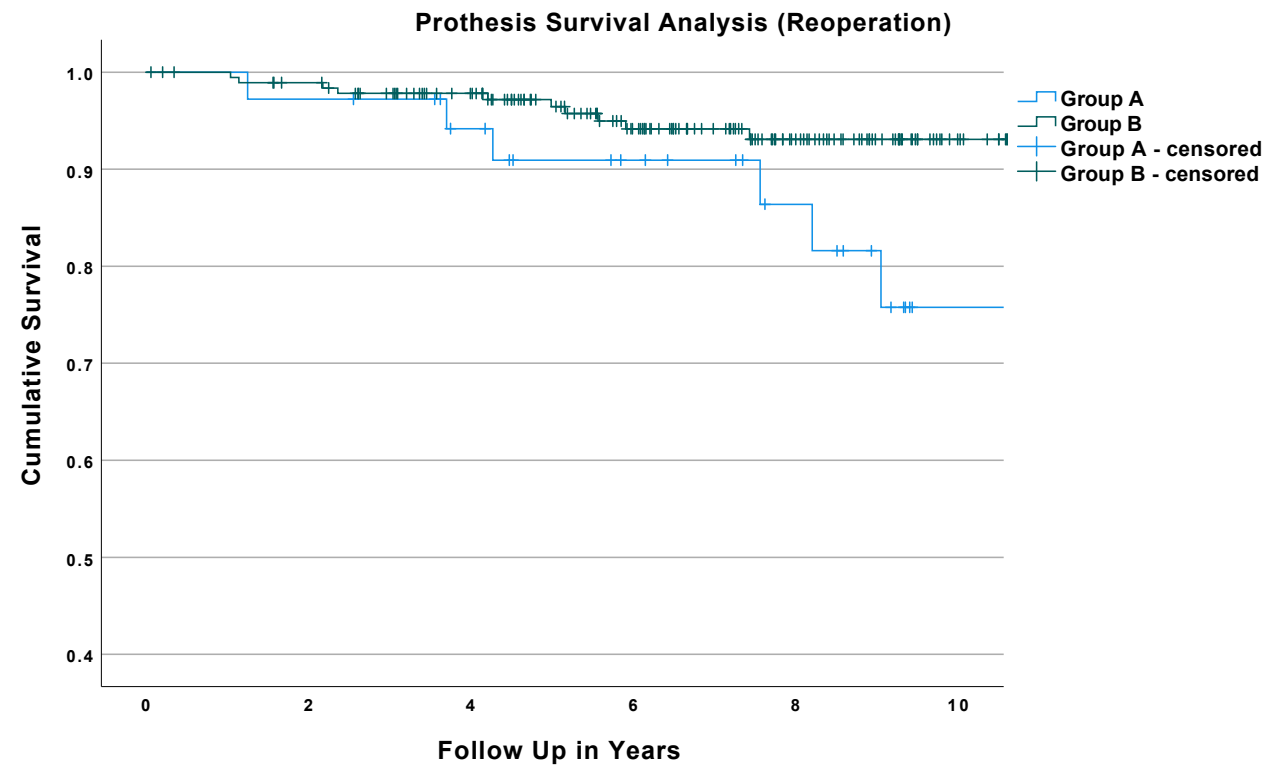

(a)

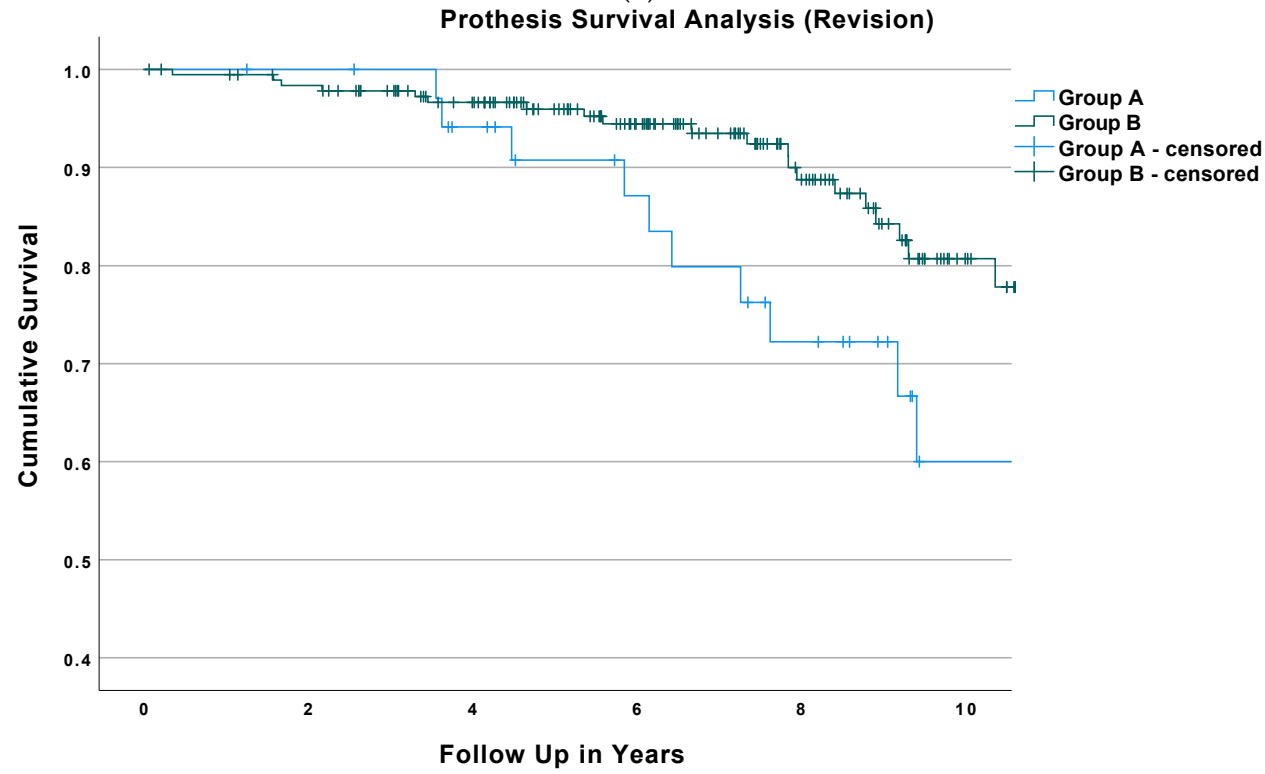

(b)

Figure 2. Cont. 


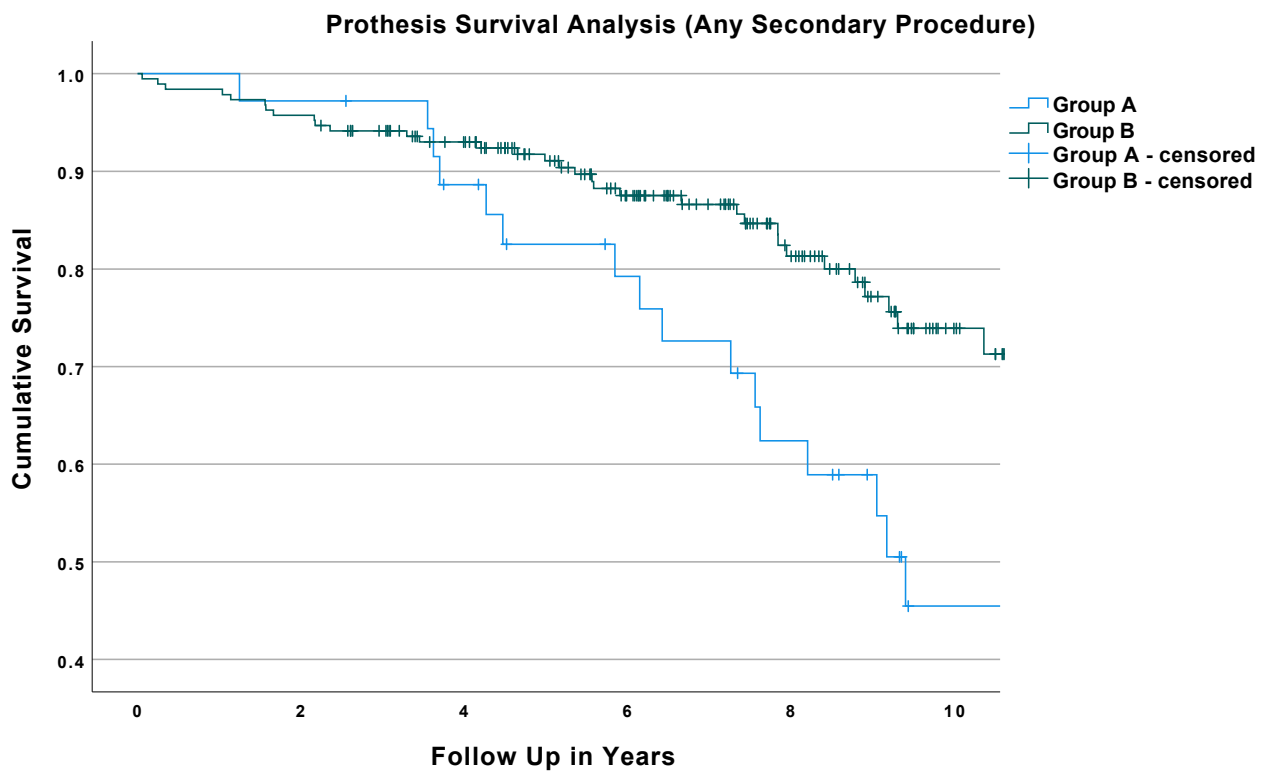

(c)

Figure 2. (a). Results of the Kaplan-Meier Survival analysis of both study groups with reoperation as the endpoint. (b) Results of the Kaplan-Meier Survival analysis of both study groups with revision as the endpoint. (c) Results of the Kaplan-Meier Survival analysis of both study groups with any secondary surgery as the endpoint.

The Kaplan-Meier survival analysis with revision as the endpoint revealed a 5-year survival rate of $90.8 \% \pm 5.1 \%$ for Group A and $96.0 \% \pm 1.5 \%$ for Group B. The 7-year survival rate was $79.9 \% \pm 7.4 \%$ for Group A and $93.5 \% \pm 2.0 \%$ for Group B; Figure $2 b$. The difference between the prothesis survival of Groups A and B with revision as the endpoint was significant according to the performed log rank test $(p=0.036)$.

The Kaplan-Meier survival analysis with any secondary procedure as the endpoint revealed a 5-year survival rate of $82.5 \% \pm 6.5$ for Group A and a 5-year survival rate of $91.1 \% \pm 2.1 \%$ for Group B. The 7-year survival rate was $72.6 \% \pm 7.8 \%$ for Group A and $86.6 \% \pm 2.7 \%$ for Group B; see Figure $2 \mathrm{c}$. The difference between the prothesis survival rate with any secondary surgery as the endpoint of Groups A and B was significant according to the performed log rank test $(p=0.003)$.

The binary logistic regression performed within the study population revealed an odds ratio of $6.54(95 \%$ CI: 1.96-21.8; $p=0.002)$ for reoperations, an odds ratio of $3.13(95 \%$ CI: $1.22-8.04 ; p=0.018)$ for revision, and an odds ratio of 5.35 (95\% CI: $2.24-12.80 ; p>0.001)$ for any secondary procedure for Group A. The binary logistic regression performed on patient characteristics within the whole study population revealed an odds ratio for every additional year of age of 0.94 (95\% CI: $0.90-0.99 ; p=0.009)$ for reoperations, an odds ratio for every additional year of age of 0.94 (95\% CI: $0.90-0.97 ; p=0.001)$ for revisions, and an odds ratio for every additional year of age of 0.93 (95\% CI: $0.90-0.96 ; p>0.001)$ for any secondary procedures. No other analyzed patient characteristics showed a significant effect on the reoperation or revision rates. See Table 4 for the detailed results of the logistic regression. 
Table 4. Results of the binary logistic regression reporting the odds ratio for reoperation, revision, and any secondary procedure of each patient characteristic with the $95 \% \mathrm{CI}$ and level of significance in brackets.

\begin{tabular}{cccc}
\hline Characteristic & Reoperation & Revision & Any Sec. Procedure \\
\hline Age (years) & $0.94(0.90-0.99 ; p=0.009)$ & $0.94(0.90-0.97 ; p=0.001)$ & $0.93(0.90-0.96 ; p>0.001)$ \\
\hline Sex (male) & $1.38(0.32-5.90 ; p=0.664)$ & $1.24(0.42-3.68 ; p=0.705)$ & $1.25(0.49-3.20 ; p=0.639)$ \\
\hline Body height $(\mathrm{cm})$ & $1.09(0.70-1.70 ; p=0.703)$ & $1.01(0.92-1.18 ; p=0.796)$ & $1.02(0.92-1.14 ; p=0.698)$ \\
\hline Body weight $(\mathrm{kg})$ & $0.89(0.56-1.42 ; p=0.603)$ & $1.01(0.90-1.15 ; p=0.838)$ & $0.99(0.87-1.12 ; p=0.830)$ \\
\hline Body Mass Index & $1.27(0.33-4.93 ; p=0.726)$ & $0.94(0.65-1.36 ; p=0.747)$ & $0.98(0.68-1.42 ; p=0.918)$ \\
\hline ASA-Score & $1.23(0.47-3.20 ; p=0.678)$ & $1.48(0.69-3.18 ; p=0.320)$ & $1.27(0.65-2.48 ; p=0.490)$ \\
\hline
\end{tabular}

\section{Discussion}

The results of this study revealed a significantly higher rate of secondary procedures related to TAA for patients aged under 50 years at time of surgery compared to patients aged 50 years or above at time of surgery. The overall secondary procedure rate was $58.3 \%$ in Group A and 26.8\% in Group B (less than half compared to Group A). Additionally, the binary logistic regression performed within the whole study population independently from the patients' allocation to the two study groups showed a significant effect of age on the rate of secondary procedures within the FU.

These findings confirm that the prevalent opinion of some authors, who have described the ideal patient eligible for TAA as relatively old with low physical demands [10,28-30], can also be applied for modern TAA implants. Similar to other joint arthroplasties, such as total hip arthroplasty and total knee arthroplasty, young patient age has been found to be associated with an increased revision rate many times [31-35].

Nevertheless, some recent studies regarding modern TAA have questioned the indication of TAA in young patients. Satisfying outcomes including implant survival and reoperation rates with no significant difference to older patients have been more often reported recently [17-20,22,23], which is clearly in contrast to the findings of this study. For example, a retrospective cohort study conducted by Gaugler et al. using the Hintegra implant in a cohort of 811 patients revealed no significant effect of age on the rates for minor or major revisions, while the clinical outcomes of younger and older patients were comparable with slightly better pain relief in older patients [20]. Similarly, Lee et al. reported no significant difference in revisions rates and clinical outcomes related to age at time of surgery when using the Hintegra implant in a cohort of 117 patients [17].

Demetracopoulos et al. prospectively analyzed several different TAA implants and found no significant difference regarding complication and reoperation rates related to age at time of surgery in a cohort of 395 patients [22]. Rodrigues-Pinto et al., who investigated the same TAA implant as the present study, conducted a prospective multicentric study in a cohort of 103 patients and found no significant differences in revision rates and implant survival between patients aged below or above 50 years at time of surgery, while significantly better clinical outcomes were found postoperatively in patients aged below 50 years at time of surgery [18]. Cottom et al. investigated several different implants in 112 patients and reported the following complication rates: $18 \%$ for patients younger than 55 years, $11.6 \%$ for patients aged between 55 and 70 years, and $9.4 \%$ for patients older than 70 years at time of surgery. At a mean follow up of 33.9 months, those differences regarding complication rates were not statistically significant [19].

Apart from Gaugler et al. (811 TAAs; 5.4-6.9 years mean FU), the studies mentioned above featured either a shorter mean FU or a smaller study population (Lee et al.: 6.5 years and 117 TAAs; Demetracopoulos et al.: 3.5 years and 395 TAAs; Rodrigues-Pinto et al.: 3.4 years and 103 TAAs; and Cottom et al.: 2.8 years and 112 TAAs). The length of the mean FU seems to be an important factor in age-related revision rates after TAA, as within the 
survival analysis of our study population, the survival rate between the two groups was very much alike until approximately 4 years after surgery, with a notable greater decline of the survival rate of Group A following the 4th year after surgery (Figure 2a-c). Additionally, except for that of Rodrigues-Pinot et al., the studies mentioned above investigated different implants than this study. All of these differences complicate the comparability between these studies and may explain the heterogenous age-related outcomes and reoperations rates reported in the literature.

All the studies mentioned above investigated a possible association between patient age at time of surgery and complication rate. Although some of those studies-such as the study conducted by Cottom et al. [19] —implied tendencies towards higher complication rates in young patients, none of those studies found a statistically significant association between patient age at time of surgery and complication rate.

Due to the study design, we were not able to determine causal reasons for the higher rate of complications and secondary procedures of younger patients within the study population. However, one factor contributing to the higher complication rate might be an averagely higher physical demand and more intensive physical activities of younger patients, which might cause the accelerated wear of prothesis' components and increased periarticular soft tissue and bone affection [36-40]. Due to the study design and the limitations mentioned below, we were also not able to reliably comment on the occurrence of OA of adjacent joints after TAA. Due to residual mobility, OA of adjacent joints should in theory occur less often after TAA than after ankle arthrodesis [11,12]. However, there is a lack of studies directly comparing OA of adjacent joints after TAA and ankle arthrodesis, such as in a prospective randomized controlled trial setting [13-16]. Additionally, different rates of OA of adjacent joints after ankle arthrodesis have been reported in the literature [41]. Additionally, there seem to be differences between different types of ankle arthrodeses, e.g., Morasiewicz et al. found a lower rate of OA in adjacent joints after using an external Ilizarov fixation for ankle arthrodesis compared to an internal fixation for ankle arthrodesis [42]. To further evaluate this matter, more studies with appropriate study designs are necessary.

This study had several limitations that must be kept in mind when interpreting its findings. The retrospective study design was a major limitation, as no causal conclusions could be drawn from the results. Additionally, no clinical outcome measures or radiographic outcomes were analyzed within this study. Therefore, we were not able to comment on the clinical and radiological outcomes including patient satisfaction within the study population. For future investigations, a prospective study design including patient-reported outcome measures would be more appropriate to thoroughly analyze the effects of certain patient characteristics, such as physical activity, on the revision rates and overall outcomes after TAA. A total of 40 protheses could not be included in the study due to a lack of the minimum FU of 2 years, which represents another limitation, as does the unequal distribution of the number of patients between the two study groups. One possible explanation for the unequal distribution might be the higher prevalence of $\mathrm{OA}$ in older patients in general $[43,44]$. Furthermore, it was not possible to retrospectively determine the duration of each surgery. Therefore, we were not able to comment on a possible influence of duration of surgery on the outcome, specifically the reoperation and revision rates.

\section{Conclusions}

The ideal indication for TAA remains controversial, especially when it comes to the treatment of patients aged under 50 years. The findings of this study show a high reoperation rate in young patients. More than half of young patients underwent secondary surgery within a mean FU of 7 years within our study population. Therefore, the outcomes of this study suggest that the indication for TAA in patients aged under 50 years should be considered very carefully and that the association between low patient age and high reoperation rate should be disclosed to all eligible patients. 


\begin{abstract}
Author Contributions: Conceptualization, C.S.; methodology, C.S. and A.K.; data curation, C.S., M.L., S.S. and M.G.; writing-original draft preparation, C.S. and L.P.; writing-review and editing, T.G., A.K. and M.C.K.; supervision, M.C.K. All authors have read and agreed to the published version of the manuscript.
\end{abstract}

Funding: Open Access Funding by the University of Linz.

Institutional Review Board Statement: The study was conducted in accordance with the Declaration of Helsinki and approved by the Ethics Committee of the Medical Faculty at Johannes Kepler University Linz (Study Number: 1270/2020; Date of approval: 12 January 2021).

Informed Consent Statement: Informed consent was obtained from all subjects involved in the study.

Data Availability Statement: The data presented in this study are available on request from the corresponding author.

Conflicts of Interest: The authors declare no conflict of interest.

\title{
References
}

1. Espinosa, N.; Klammer, G. Treatment of Ankle Osteoarthritis: Arthrodesis versus Total Ankle Replacement. Eur. J. Trauma Emerg. Surg. 2010, 36, 525-535. [CrossRef] [PubMed]

2. Grunfeld, R.; Aydogan, U.; Juliano, P. Ankle Arthritis: Review of Diagnosis and Operative Management. Med. Clin. N. Am. 2014, 98, 267-289. [CrossRef] [PubMed]

3. Norvell, D.C.; Ledoux, W.R.; Shofer, J.B.; Hansen, S.T.; Davitt, J.; Anderson, J.G.; Bohay, D.; Coetzee, J.C.; Maskill, J.; Brage, M.; et al. Effectiveness and Safety of Ankle Arthrodesis Versus Arthroplasty: A Prospective Multicenter Study. J. Bone Jt. Surg. Am. 2019, 101, 1485-1494. [CrossRef] [PubMed]

4. Sanders, A.E.; Kraszewski, A.P.; Ellis, S.J.; Queen, R.; Backus, S.I.; Hillstrom, H.; Demetracopoulos, C.A. Differences in Gait and Stair Ascent After Total Ankle Arthroplasty and Ankle Arthrodesis. Foot Ankle Int. 2020, 42, 347-355. [CrossRef] [PubMed]

5. Lawton, C.D.; Butler, B.A.; Dekker, R.G.; Prescott, A.; Kadakia, A.R. Total Ankle Arthroplasty versus Ankle Arthrodesis-A Comparison of Outcomes over the Last Decade. J. Orthop. Surg. Res. 2017, 12, 76. [CrossRef]

6. Seaworth, C.; Do, H.; Vulcano, E.; Mani, S.; Lyman, S.; Ellis, S. Epidemiology of Total Ankle Arthroplasty: Trends in New York State. Orthopedics 2016, 39, 170-176. [CrossRef]

7. Jeyaseelan, L.; Si-Hyeong Park, S.; Al-Rumaih, H.; Veljkovic, A.; Penner, M.J.; Wing, K.J.; Younger, A. Outcomes Following Total Ankle Arthroplasty: A Review of the Registry Data and Current Literature. Orthop. Clin. N. Am. 2019, 50, 539-548. [CrossRef]

8. McKenna, B.J.; Cook, J.; Cook, E.A.; Crafton, J.; Knabel, M.; Swenson, E.; Miner, S.; Manning, E.; Basile, P. Total Ankle Arthroplasty Survivorship: A Meta-Analysis. J. Foot Ankle Surg. 2020, 59, 1040-1048. [CrossRef]

9. Vakhshori, V.; Sabour, A.F.; Alluri, R.K.; Hatch, G.F.I.; Tan, E.W. Patient and Practice Trends in Total Ankle Replacement and Tibiotalar Arthrodesis in the United States From 2007 to 2013. JAAOS—J. Am. Acad. Orthop. Surg. 2019, 27, e77-e84. [CrossRef]

10. Krause, F.G.; Schmid, T. Ankle Arthrodesis versus Total Ankle Replacement: How Do I Decide? Foot Ankle Clin. $2012,17,529-543$. [CrossRef]

11. Pedowitz, D.I.; Kane, J.M.; Smith, G.M.; Saffel, H.L.; Comer, C.; Raikin, S.M. Total Ankle Arthroplasty versus Ankle Arthrodesis. Bone Jt. J. 2016, 98, 634-640. [CrossRef] [PubMed]

12. Thomas, R.; Daniels, T.R.; Parker, K. Gait Analysis and Functional Outcomes Following Ankle Arthrodesis for Isolated Ankle Arthritis. JBJS 2006, 88, 526-535. [CrossRef]

13. SooHoo, N.F.; Zingmond, D.S.; Ko, C.Y. Comparison of Reoperation Rates Following Ankle Arthrodesis and Total Ankle Arthroplasty. J. Bone Jt. Surg. Am. 2007, 89, 2143-2149. [CrossRef]

14. Dekker, T.J.; Walton, D.; Vinson, E.N.; Hamid, K.S.; Federer, A.E.; Easley, M.E.; DeOrio, J.K.; Nunley, J.A.; Adams, S.B. Hindfoot Arthritis Progression and Arthrodesis Risk After Total Ankle Replacement. Foot Ankle Int. 2017, 38, 1183-1187. [CrossRef]

15. Ross, B.J.; Savage-Elliott, I.; Wu, V.J.; Rodriguez, R.F. Complications Following Total Ankle Arthroplasty Versus Ankle Arthrodesis for Primary Ankle Osteoarthritis. Foot Ankle Spec. 2021, 1938640020987741. [CrossRef]

16. Stavrakis, A.I.; SooHoo, N.F. Trends in Complication Rates Following Ankle Arthrodesis and Total Ankle Replacement. JBJS 2016, 98, 1453-1458. [CrossRef]

17. Lee, G.-W.; Seon, J.; Kim, N.-S.; Lee, K.-B. Comparison of Intermediate-Term Outcomes of Total Ankle Arthroplasty in Patients Younger and Older Than 55 Years. Foot Ankle Int. 2019, 40, 762-768. [CrossRef]

18. Rodrigues-Pinto, R.; Muras, J.; Martín Oliva, X.; Amado, P. Total Ankle Replacement in Patients under the Age of 50. Should the Indications Be Revised? Foot Ankle Surg. 2013, 19, 229-233. [CrossRef]

19. Cottom, J.M.; Graney, C.T.; Douthett, S.M.; Sisovsky, C.; McConnell, K.K.; Plemmons, B.S. Age-Related Outcomes in Total Ankle Arthroplasty: An Analysis of 112 Patients. J. Foot Ankle Surg. 2020, 59, 739-742. [CrossRef]

20. Gaugler, M.; Krähenbühl, N.; Barg, A.; Ruiz, R.; Horn-Lang, T.; Susdorf, R.; Dutilh, G.; Hintermann, B. Effect of Age on Outcome and Revision in Total Ankle Arthroplasty. Bone Jt. J. 2020, 102, 925-932. [CrossRef] 
21. Tenenbaum, S.; Bariteau, J.; Coleman, S.; Brodsky, J. Functional and Clinical Outcomes of Total Ankle Arthroplasty in Elderly Compared to Younger Patients. Foot Ankle Surg. 2017, 23, 102-107. [CrossRef] [PubMed]

22. Demetracopoulos, C.A.; Adams, S.B.; Queen, R.M.; DeOrio, J.K.; Nunley, J.A.; Easley, M.E. Effect of Age on Outcomes in Total Ankle Arthroplasty. Foot Ankle Int. 2015, 36, 871-880. [CrossRef] [PubMed]

23. Consul, D.W.; Chu, A.; Langan, T.M.; Hyer, C.F.; Berlet, G. Total Ankle Arthroplasty Survivorship, Complication, and Revision Rates in Patients Younger Than 55 Years. Foot Ankle Spec. 2021. [CrossRef] [PubMed]

24. Cianni, L.; Bocchi, M.B.; Vitiello, R.; Greco, T.; De Marco, D.; Masci, G.; Maccauro, G.; Pitocco, D.; Perisano, C. Arthrodesis in the Charcot Foot: A Systematic Review. Orthop. Rev. 2020, 12, 8670. [CrossRef]

25. Colombier, J.A.; Judet, T.; Bonnin, M.; Gaudot, F. Techniques and Pitfalls with the Salto Prosthesis: Our Experience of the First 15 Years. Foot Ankle Clin. 2012, 17, 587-605. [CrossRef]

26. Bonnin, M.; Judet, T.; Colombier, J.A.; Buscayret, F.; Graveleau, N.; Piriou, P. Midterm Results of the Salto Total Ankle Prosthesis. Clin. Orthop. Relat. Res. 2004, 424, 6-18. [CrossRef]

27. Henricson, A.; Carlsson, A.; Rydholm, U. What Is a Revision of Total Ankle Replacement? Foot Ankle Surg. 2011, 17, 99-102. [CrossRef]

28. Saltzman, C. Total Ankle Arthroplasty: State of the Art. Instr. Course Lect. 1999, 48, 263-268.

29. Samaila, E.M.; Bissoli, A.; Argentini, E.; Negri, S.; Colò, G.; Magnan, B. Total Ankle Replacement in Young Patients. Acta Biomed. 2020, 91, 31-35. [CrossRef]

30. Hintermann, B.; Knupp, M.; Zwicky, L.; Barg, A. Total Ankle Replacement for Treatment of End-Stage Osteoarthritis in Elderly Patients. J. Aging Res. 2012, 2012, 345237. [CrossRef]

31. Pitta, M.; Esposito, C.I.; Li, Z.; Lee, Y.; Wright, T.M.; Padgett, D.E. Failure After Modern Total Knee Arthroplasty: A Prospective Study of 18,065 Knees. J. Arthroplast. 2018, 33, 407-414. [CrossRef] [PubMed]

32. Bottle, A.; Parikh, S.; Aylin, P.; Loeffler, M. Risk Factors for Early Revision after Total Hip and Knee Arthroplasty: National Observational Study from a Surgeon and Population Perspective. PLoS ONE 2019, 14, e0214855. [CrossRef] [PubMed]

33. Boyer, B.; Bordini, B.; Caputo, D.; Neri, T.; Stea, S.; Toni, A. What Are the Influencing Factors on Hip and Knee Arthroplasty Survival? Prospective Cohort Study on 63619 Arthroplasties. Orthop. Traumatol. Surg. Res. 2019, 105, 1251-1256. [CrossRef] [PubMed]

34. Bayliss, L.E.; Culliford, D.; Monk, A.P.; Glyn-Jones, S.; Prieto-Alhambra, D.; Judge, A.; Cooper, C.; Carr, A.J.; Arden, N.K.; Beard, D.J.; et al. The Effect of Patient Age at Intervention on Risk of Implant Revision after Total Replacement of the Hip or Knee: A Population-Based Cohort Study. Lancet 2017, 389, 1424-1430. [CrossRef]

35. Namba, R.S.; Cafri, G.; Khatod, M.; Inacio, M.C.S.; Brox, T.W.; Paxton, E.W. Risk Factors for Total Knee Arthroplasty Aseptic Revision. J. Arthroplast. 2013, 28, 122-127. [CrossRef]

36. Schmalzried, T.P.; Shepherd, E.F.; Dorey, F.J.; Jackson, W.O.; dela Rosa, M.; Fa'vae, F.; McKellop, H.A.; McClung, C.D.; Martell, J.; Moreland, J.R.; et al. The John Charnley Award. Wear Is a Function of Use, Not Time. Clin. Orthop. Relat. Res. 2000, 381, 36-46. [CrossRef]

37. Chakravarty, R.; Elmallah, R.D.K.; Cherian, J.J.; Kurtz, S.M.; Mont, M.A. Polyethylene Wear in Knee Arthroplasty. J. Knee Surg. 2015, 28, 370-375. [CrossRef]

38. Naudie, D.D.R.; Ammeen, D.J.; Engh, G.A.; Rorabeck, C.H. Wear and Osteolysis Around Total Knee Arthroplasty. JAAOS-J. Am. Acad. Orthop. Surg. 2007, 15, 53-64. [CrossRef]

39. Schmalzried, T.P.; Szuszczewicz, E.S.; Northfield, M.R.; Akizuki, K.H.; Frankel, R.E.; Belcher, G.; Amstutz, H.C. Quantitative Assessment of Walking Activity after Total Hip or Knee Replacement. J. Bone Jt. Surg. Am. 1998, 80, 54-59. [CrossRef]

40. Cherian, J.J.; Jauregui, J.J.; Banerjee, S.; Pierce, T.; Mont, M.A. What Host Factors Affect Aseptic Loosening After THA and TKA? Clin. Orthop. Relat. Res. 2015, 473, 2700-2709. [CrossRef]

41. Ling, J.S.; Smyth, N.A.; Fraser, E.J.; Hogan, M.V.; Seaworth, C.M.; Ross, K.A.; Kennedy, J.G. Investigating the Relationship Between Ankle Arthrodesis and Adjacent-Joint Arthritis in the Hindfoot: A Systematic Review. JBJS 2015, 97, e43. [CrossRef] [PubMed]

42. Morasiewicz, P.; Dejnek, M.; Urbański, W.; Dragan, S.Ł.; Kulej, M.; Dragan, S.F. Radiological Evaluation of Ankle Arthrodesis with Ilizarov Fixation Compared to Internal Fixation. Injury 2017, 48, 1678-1683. [CrossRef] [PubMed]

43. Neogi, T.; Zhang, Y. Epidemiology of Osteoarthritis. Rheum. Dis. Clin. N. Am. 2013, 39, 1-19. [CrossRef] [PubMed]

44. Thomas, M.J.; Roddy, E.; Zhang, W.; Menz, H.B.; Hannan, M.T.; Peat, G.M. The Population Prevalence of Foot and Ankle Pain in Middle and Old Age: A Systematic Review. Pain 2011, 152, 2870-2880. [CrossRef] [PubMed] 